BMC

Neuroscience

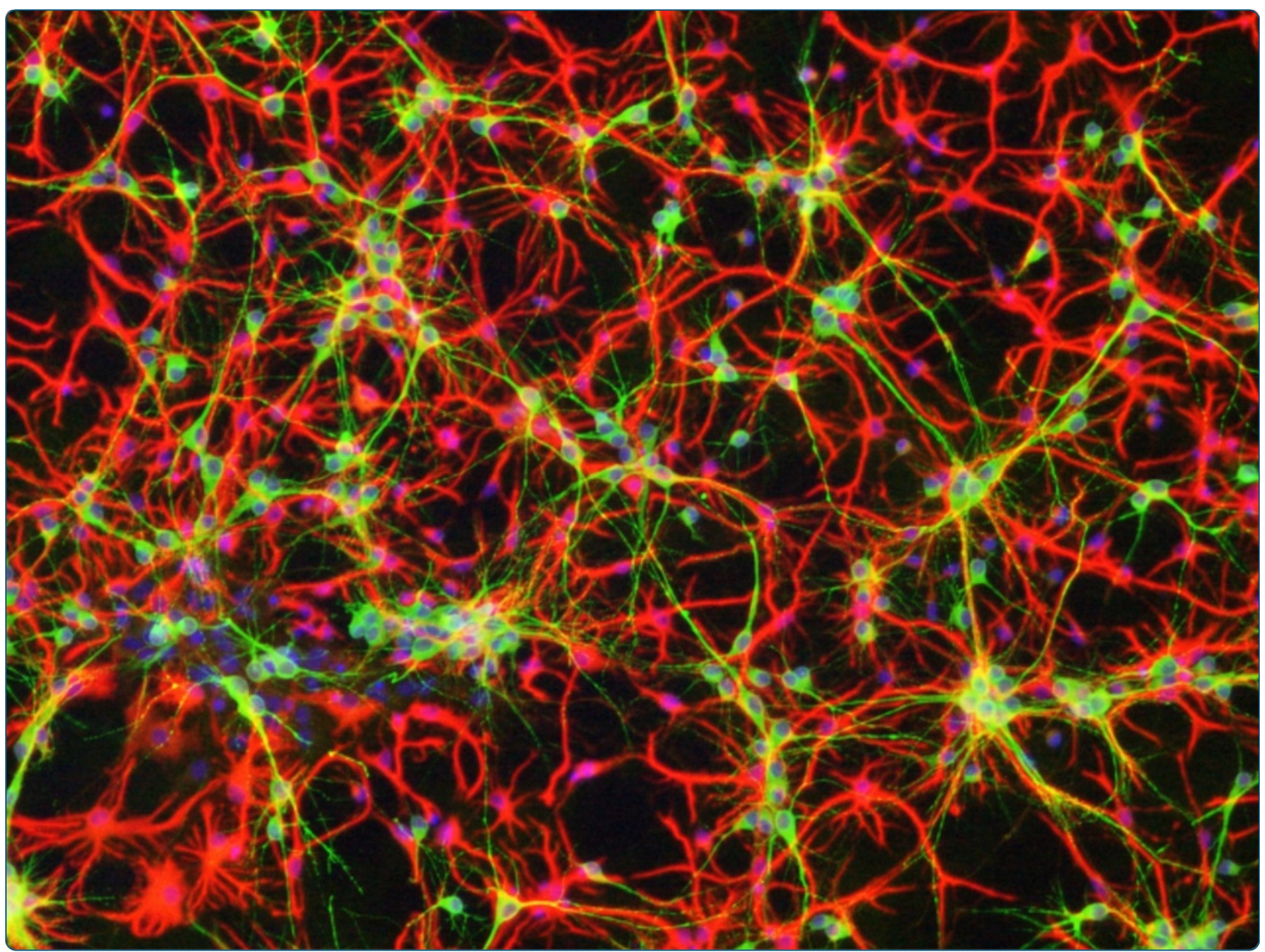

A neural extracellular matrix-based method for in vitro hippocampal neuron culture and dopaminergic differentiation of neural stem cells

García-Parra et al.

C Biomed Central

García-Parra et al. BMC Neuroscience 2013, 14:48

http://www.biomedcentral.com/1471-2202/14/48 


\title{
A neural extracellular matrix-based method for in vitro hippocampal neuron culture and dopaminergic differentiation of neural stem cells
}

\author{
Patricia García-Parra ${ }^{1,2^{*}}$, Marcos Maroto $^{3}$, Fabio Cavaliere ${ }^{4}$, Neia Naldaiz-Gastesi ${ }^{1,2}$, José Iñaki Álava ${ }^{5}$, \\ Antonio G García ${ }^{3}$, Adolfo López de Munain ${ }^{2}$ and Ander Izeta ${ }^{1}$
}

\begin{abstract}
Background: The ability to recreate an optimal cellular microenvironment is critical to understand neuronal behavior and functionality in vitro. An organized neural extracellular matrix (nECM) promotes neural cell adhesion, proliferation and differentiation. Here, we expanded previous observations on the ability of nECM to support in vitro neuronal differentiation, with the following goals: (i) to recreate complex neuronal networks of embryonic rat hippocampal cells, and (ii) to achieve improved levels of dopaminergic differentiation of subventricular zone (SVZ) neural progenitor cells.
\end{abstract}

Methods: Hippocampal cells from E18 rat embryos were seeded on PLL- and nECM-coated substrates. Neurosphere cultures were prepared from the SVZ of P4-P7 rat pups, and differentiation of neurospheres assayed on PLL- and nECM-coated substrates.

Results: When seeded on nECM-coated substrates, both hippocampal cells and SVZ progenitor cells showed neural expression patterns that were similar to their poly-L-lysine-seeded counterparts. However, nECM-based cultures of both hippocampal neurons and SVZ progenitor cells could be maintained for longer times as compared to poly-L-lysine-based cultures. As a result, nECM-based cultures gave rise to a more branched neurite arborization of hippocampal neurons. Interestingly, the prolonged differentiation time of SVZ progenitor cells in nECM allowed us to obtain a purer population of dopaminergic neurons.

Conclusions: We conclude that nECM-based coating is an efficient substrate to culture neural cells at different stages of differentiation. In addition, neural ECM-coated substrates increased neuronal survival and neuronal differentiation efficiency as compared to cationic polymers such as poly-L-lysine.

Keywords: Neural extracellular matrix, Subventricular zone, Neuronal culture, Neural progenitor cells, Dopaminergic differentiation

\section{Background}

The extracellular matrix (ECM) is responsible for the promotion of cell adhesion, proliferation and differentiation, and hence maintenance of tissue homeostasis throughout the whole organism. In the nervous system, neural ECM (nECM) components provide the necessary cues for the growth of neurons and neurites both in vitro and in vivo

\footnotetext{
* Correspondence: patricia.garcia@biodonostia.org

${ }^{1}$ Tissue Engineering Laboratory, Department of Bioengineering, Instituto Biodonostia, Hospital Universitario Donostia, San Sebastian 20014, Spain ${ }^{2}$ Neuroscience Area and CIBERNED, Instituto Biodonostia, Hospital Universitario Donostia, San Sebastian 20014, Spain

Full list of author information is available at the end of the article
}

[1]. Even during embryonic development, nECM plays a major role in the formation and expansion of the neural crest [2,3]. Although mature $\mathrm{nECM}$ is amorphous, it also contains dense areas around neurons known as perineural networks (PNNs), which in turn leave spaces at the sites where synaptic contacts are established $[4,5]$. PNNs are mainly composed of proteoglycans, collagen, laminin, fibronectin and neuropeptides. The latter seem to be involved in the regulation of neuronal plasticity [6] as well as in neuroprotection [7].

Topographical and biochemical characteristics of the substrate might thus be critical for axonal outgrowth

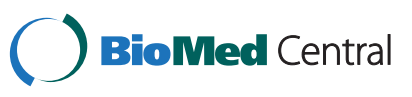


and regeneration of neural circuits in vivo. For instance, cell therapy trials of Parkinson's disease indicate that the mere existence of a damaged microenvironment promotes the generation of new dopaminergic neurons, although perhaps in numbers insufficient for clinical improvement [8].

In the adult central nervous system (CNS), neurogenesis seems to be restricted to two specific areas: (i) the subventricular zone (SVZ) $[9,10]$ and (ii) the subgranular layer of the dentate gyrus of the hippocampus [11,12]. Neural stem cells (NSCs) with multipotent potential can be derived from rodent SVZ $[10,11,13]$. In vitro, the differentiation of NSCs into neuronal or glial cells is induced in adherent culture conditions (with serum) after EGF and FGF2 withdrawal and by specific neuronal- and/or glialinducing factors. As the differentiation process progresses, NSCs restrict their ability to self-renew and differentiate to other lineages.

In a previous article we described the development, characterization and functional validation of a nECM-based polymeric support used as a biocompatible and efficient in vitro microenvironment for neuronal differentiation of both PC12 cells and adult skin-derived precursor cells [14]. Since nECM proteoglycans are involved in axonal regeneration and in post-traumatic neuronal plasticity in the CNS $[15,16]$, the rationale for the present methodological article was to use the $\mathrm{nECM}$ component of this polymeric support to study neuronal development and, in particular, dopaminergic differentiation. The presence of collagen, laminin, entactin and certain proteoglycans in the basal composition of nECM provides the signals that cells need to be anchored to the substrate and start differentiation. Moreover, hyaluronic acid enhances the hydration of the matrix, which in turn will facilitate cell movement and neurite extension along the neuronal differentiation progress as well as provide fixation sites for growth factors [17] and other glycosaminoglycan-binding molecules [18]. Finally, netrins support neuronal differentiation acting as cellular and neurite-chemoattractant factors, as it occurs in the naturally developing neural tissue [19].

As of today, several types of polymeric supports have been described to sustain neural cell adhesion and migration $[20,21]$. Recent works demonstrated that polymeric substrates sustain differentiation of stem/progenitor cells and help generate functional synapses because the spatial, mechanical and biochemical cues that neurons receive from the environment strongly determine their in vitro behaviour [22-25]. Nevertheless, these studies also suggest the importance of soluble factors released from the ECM. Therefore, culturing stem/progenitor cells on three-dimensional ECMs could be a successful approach to maintain multipotent progenitor cell cultures for longer in vitro, as well as to achieve higher percentages of neuronal differentiation. In the present work, we studied biocompatibility and neuronal differentiation of primary neural cells at different stages of development on nECM-coated substrates. We were particularly interested in improving primary neuronal cultures of embryonic rat hippocampal cells and to obtain higher levels of dopaminergic neurons from neonatal rat SVZ multipotent progenitor cells, as compared to more "classical" cell culture conditions such as poly-L-lysine (PLL) coating.

\section{Results and discussion}

Culture of rat hippocampal cells on neural extracellular matrix (nECM)-coated surfaces

To evaluate the effect of nECM on primary hippocampal cultures as compared to more traditional cell substrates as PLL, E18 rat embryo hippocampi were extracted, dissected and cells seeded either on nECM- or PLL-coated coverslips. As expected, a neural network (neuronal plus glial) was progressively established during the first 7 days of culture on both PLL- and nECM-based substrates (Figure 1). Culture progression (in terms of cell fate determination and neuronal sprouting) was apparently faster on $\mathrm{nECM}$ than in PLL, as visualized by immunofluorescent detection of the mature neuronal marker MAP2 and the glial marker GFAP (Figure 1B-C). A proliferative advantage (as seen by Hoechst positive cell counts) was detected on $\mathrm{nECM}$ at early time points $(\mathrm{p}<0.01$; Figure $2 \mathrm{~A})$, which was apparently lost at day 7 of culture, presumably due to cells reaching confluence. Interestingly, the number of cells committed to the neuronal lineage (MAP2+ cells, Figure 2B) was similar on both substrates at day 1-3, while cells were actively growing. However the number of neurons was significantly higher $(47.6 \pm 3.5 \%$ vs $21.2 \pm$ $4.6 \%$, respectively; $\mathrm{p}<0.001$ ) on $\mathrm{nECM}$ than in PLL at day 7 , when cultures were fully committed to differentiation. Furthermore, we observed the reverse effect $(\mathrm{p}<0.01)$ on glial lineage-committed cells (GFAP+, Figure 2C), so it can be said that $\mathrm{nECM}$ promoted neuronal differentiation while PLL favoured glial commitment.

With regard to neuronal sprouting, after 24 and $72 \mathrm{~h}$ of culture on $\mathrm{nECM}$, significant increases in the percentage of neurons sprouting neurites compared with their PLL counterparts were detected (Figure 2D). Moreover, these neurons extended a significantly higher total number of neurites $(\mathrm{p}<0.001$; Figure $2 \mathrm{E})$ and a significantly higher $(\mathrm{p}<0.001)$ number of neurites per neuron $(4.8 \pm 0.8$ vs $2.8 \pm 0.4$ neurites per neuron at day 3 , respectively; Figure 2F) than those on PLL-coated coverslips. Finally, nECM-based cultures were maintained for up to 30 days with cell media changed every 7 days (as compared to 2day media changes in the case of PLL; data not shown). These data might support a role of netrins in cell survival as previously suggested by Tang and colleagues [26]. Moreover, since netrins are known to induce neuronal sprouting during embryonic development, this effect 


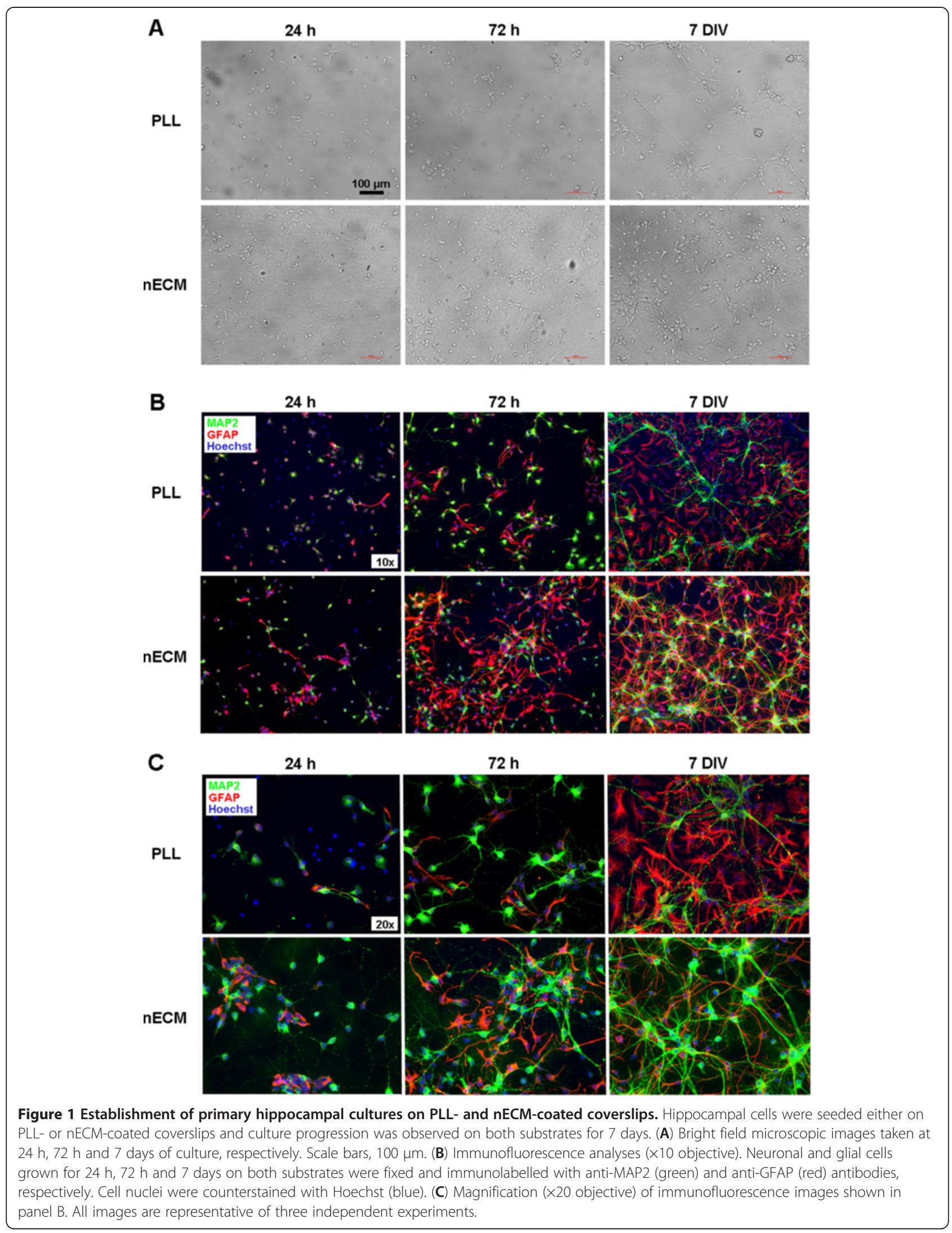




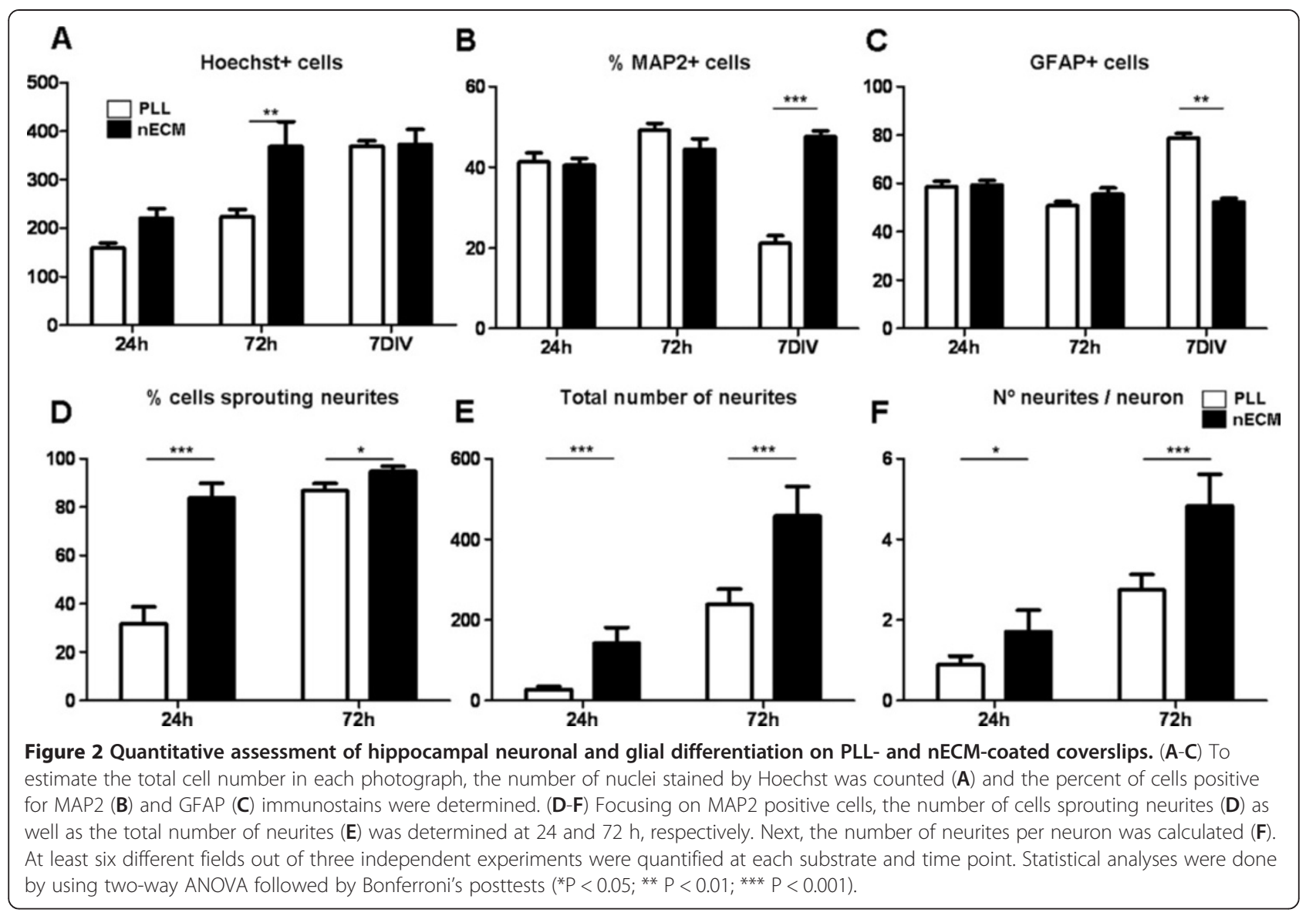

might also be observed in the adult and partially help to explain the differences in neurite number in the presence (nECM) or absence (PLL) of added netrins. Additionally, cationic polymers such as PLL may be easily digested by cells, whereas a natural and more complex polymeric support such as nECM should be more efficient in sustaining cell adhesion and, consequently, might improve cell survival overall.

As a proof-of-concept study to test usefulness of the hippocampal neuron culture system in drug testing, we set to examine the effect on neuronal viability of different molecules incorporated onto nECM. Chondroitin sulfate proteoglycans (CSPGs) are extracellular matrix molecules present in both developing and adult CNS, with a conflicting role in either promoting neural growth and plasticity or restricting them [15,27]. CSPGs are significantly upregulated in glial scar and are believed to be the main cause of regeneration failure after nervous system injury, through inhibition of neuronal growth cone formation [28-30]. However, other works describe a neuroprotecting role of chondroitin 4-sulfate (CS) as a PNN component [7,31]. To illuminate this controversy, hippocampal cells were seeded on nECM in the absence or presence of two different CS concentrations incorporated as a matrix component (1.5 and $15 \mathrm{mg} / \mathrm{ml})$, and neuronal viability was measured by MTT assay at day 8 (Figure 3A). Somewhat unexpectedly, a significant $(\mathrm{p}<0.01)$ decrease in cell viability was appreciated when higher CS concentration was used (Figure $3 \mathrm{~B}$ ). This reduction in cell viability was confirmed by anti-MAP2 immunofluorescence (Figure 3F-G). In addition, and as previously reported, CS concomitantly inhibited axonal sprouting and reduced axon growth. These data would be consistent with an anti-regenerative role of chondroitin 4-sulfate, as shown specifically for chondroitin 4-sulfate but not for chondroitin 6-sulfate [32].

Once tested in isolation, the ability of CS-incorporated nECM to protect neuronal culture from cytotoxic damage (or otherwise) was analyzed. To this end, known cytotoxic compounds such as glutamate, beta-amyloid 25:35 peptide $(\mathrm{A} \beta)$ and oligomycin-rotenone $(\mathrm{O} / \mathrm{R})$ were added to cultures grown on $\mathrm{nECM}$ in the absence or presence of previously tested CS concentrations (Figure 3C-E). Higher concentration of CS significantly $(\mathrm{P}<0.01)$ increased viability of neurons that were treated with $100 \mu \mathrm{M}$ glutamate for $24 \mathrm{~h}$ (Figure $3 \mathrm{C}$ ). The same neuroprotective tendency of CS was observed for $A \beta$ and $O / R$ treatments, but no statistical significance was achieved even at higher CS dosing (Figure 3D-E). Thus, in the presence of a cytotoxic agent as glutamate, a molecule liberated by injured cells in the central nervous system, CS (and probably other 


\section{A}

$$
8 \text { DIV in either matrix }
$$

$24 \mathrm{~h}$ stressor

B

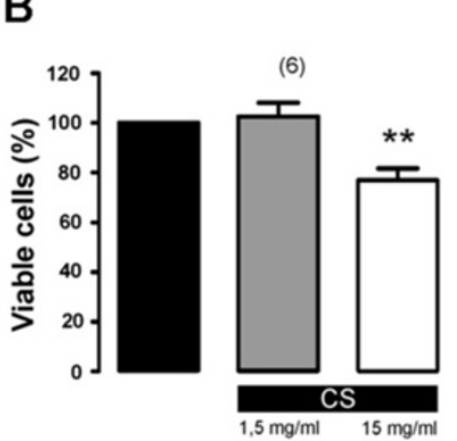

C

D
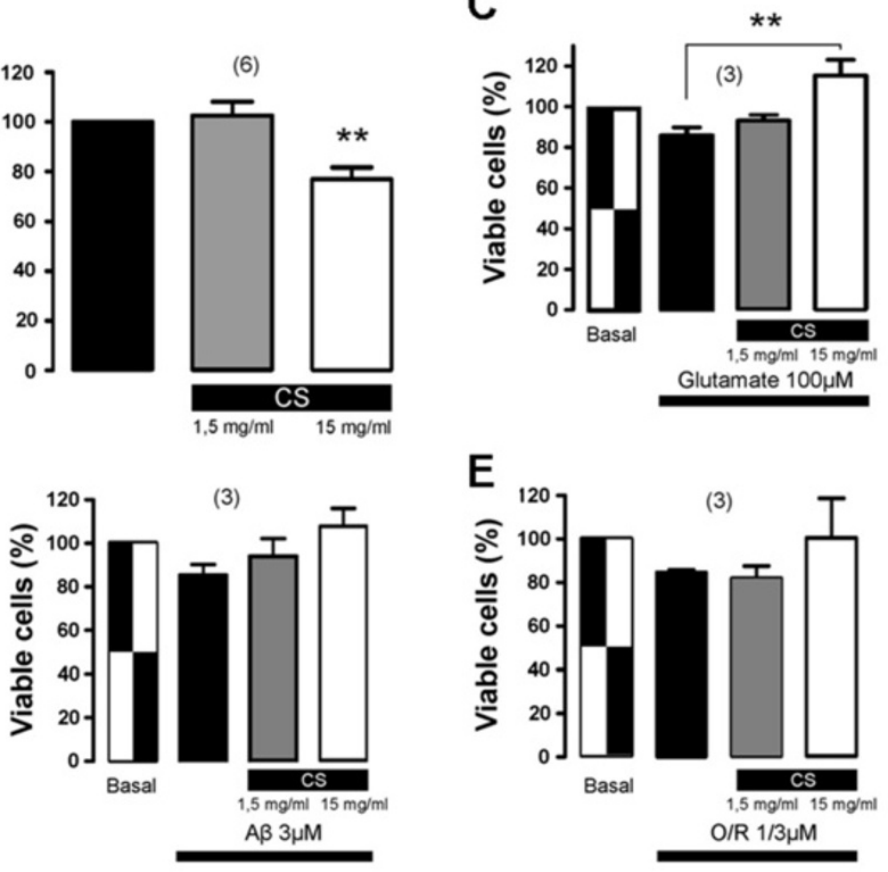

E

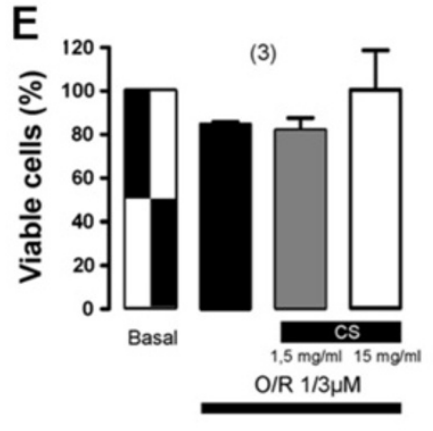

$\mathbf{F}$

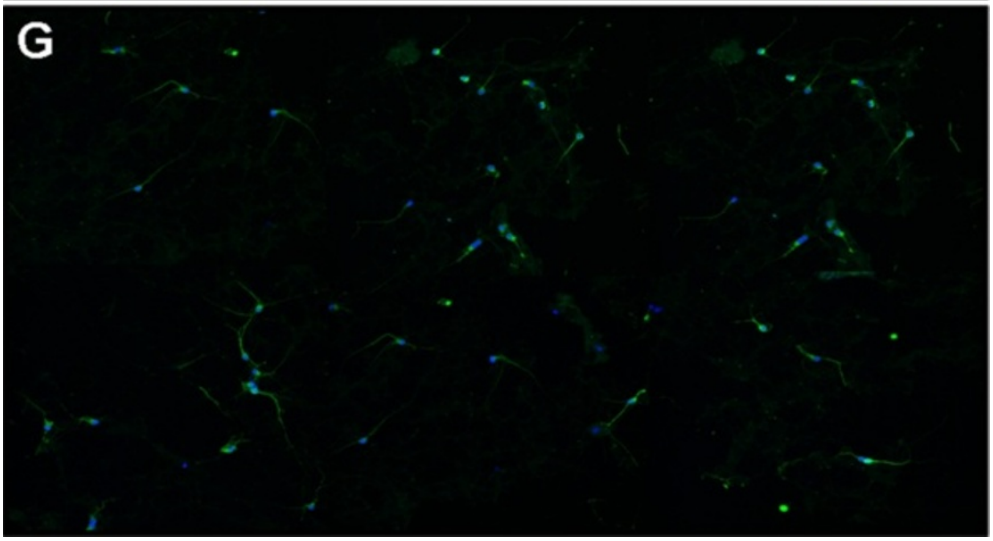

Figure 3 (See legend on next page.) 
(See figure on previous page.)

Figure 3 Effect of chondroitin 4-sulfate (CS) incorporated to nECM on hippocampal cell viability. (A) Experimental set up. After one week on CS-containing $\mathrm{nECM}$ and 24 hours of stressor treatment, hippocampus cell viability was measured by MTT assay. (B) Percentage of viability of hippocampal cells cultured on nECM in the absence (black bar) or presence of CS (1.5 mg/ml, grey bar; $15 \mathrm{mg} / \mathrm{ml}$, white bar). (C) Percentage of viability of hippocampal cells cultured on nECM in the absence/presence of CS and in the absence/presence of $100 \mu \mathrm{M}$ glutamate treatment. In each case, the treatments applied are described below bars. (D-E) Same as previous but this time in the presence of $3 \mu \mathrm{M}$ amyloid beta $23: 35$ peptide $(A \beta)(D)$ and $1 \mu \mathrm{M}$ oligomycin plus $3 \mu \mathrm{M}$ rotenone $(\mathrm{O} / \mathrm{R})(\mathbf{E})$ for $24 \mathrm{~h}$. ** $0.001<P<0.01$. The numbers between brackets on top of panels B-D show the number of independent experiments performed in each case. (F-G) Composite image containing immunofluorescence images of cells cultured on control nECM (F) and on $15 \mathrm{mg} / \mathrm{ml}$ CS-containing nECM (G). Cells were immunolabelled with anti-MAP2 antibody (green) and nuclei counterstained with Hoechst (blue).

proteoglycans present in $\mathrm{nECM}$ ) seemed to play a neuroprotective role, reversing the reduction of cellular viability seen when cells were seeded onto control nECM. Its apparent neuroprotective effect may be explained due to the known capacity of chondroitin 4-sulfate to sequester toxic compounds added to the medium. Alternatively, CS might increase the expression of antioxidant enzymes [33] or modulate the immuno-inflammatory response [31]. These observations should be studied in more detail because they could have effects on promoting repair following spinal cord injury when the ECM changes its composition and expression of CS proteoglycans is augmented [34]. Following chondroitinase $A B C$ treatment, many groups have reported some improvement in spinal cord injury models and in vitro neuronal cultures recreating glial scar ECM [35-37].

\section{Dopaminergic differentiation of subventricular zone (SVZ)-derived multipotent progenitor cells on nECM-coated surfaces}

To study a possible effect of nECM on progenitor cell differentiation, we selected a well-known neuronal differentiation protocol, starting up from multipotent progenitor cells of neonatal rat subventricular zone (SVZ). SVZ cells were isolated and expanded for 7-10 days as floating neurospheres by following previously described protocols [38], then adhered to PLL- or nECM-coated coverslips for an additional 7-10 days to yield differentiated but seemingly immature neurons (Figures 4 and 5). Figure 4 represents the differentiation procedure, which lasted a maximum of 30 days. First, immature neurons were derived for 7-10 days in the presence of neurotrophic factors NGF $\beta$ and BDNF (basic neuronal medium). Second,

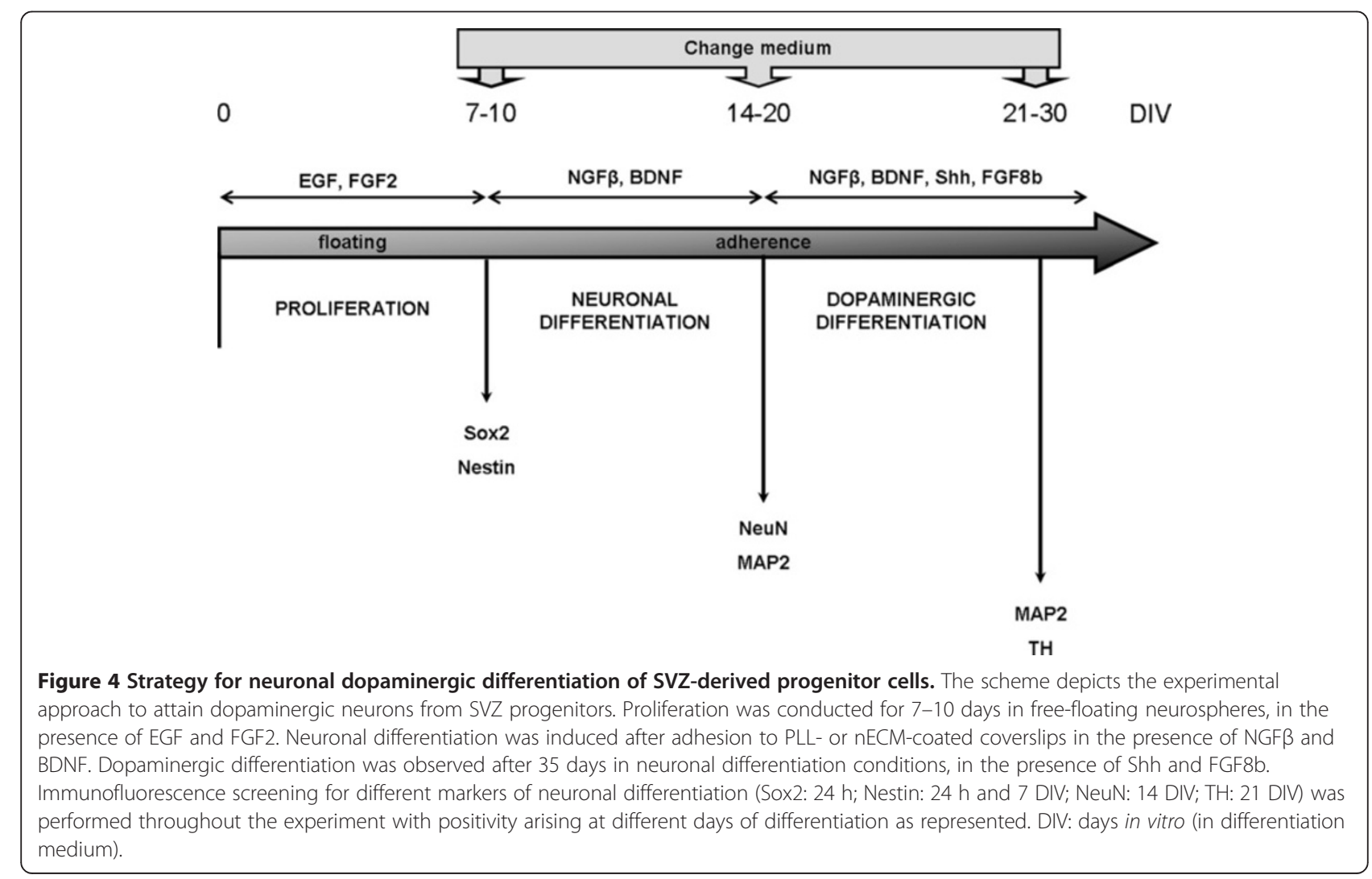




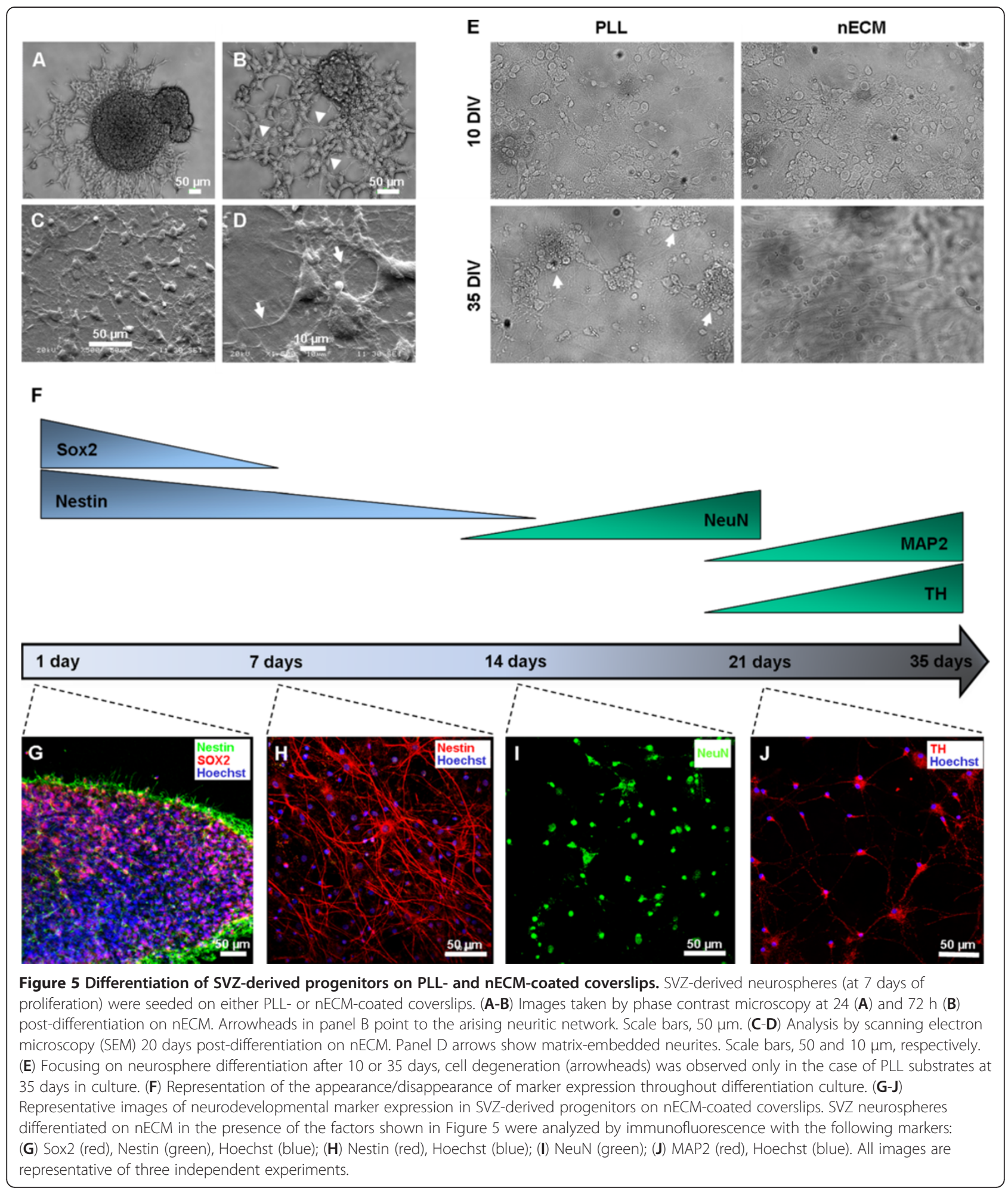

dopaminergic phenotype was induced by additional Shh and FGF8b administration (dopaminergic medium) for 710 days, as described [39-43].

The effect of nECM on neurosphere differentiation was evident as early as $24-72 \mathrm{~h}$ post-differentiation
(Figure 5A-B), in the form of radial migration of cells arising from the centre of the neurospheres and subsequent formation of neurite networks (arrowheads in Figure 5B). Scanning electron microscopy analyses (Figure 5C-D) confirmed extended neuritogenesis at day 20 of differentiation, 
newly formed neurites being often embedded by nondegraded nECM (arrows in Figure 5D). This "embedding effect" was also appreciated in Z-stack confocal views of the samples (see below). These data suggested a mechanical and trophic effect of the nECM on neuronal differentiation. On the other hand, SVZ cells started to show picnotic nuclei characteristic of cells entering apoptosis at 35 DIV (arrows in Figure 5E), a phenomenon that was not observed in nECM-based cultures.

To further characterize progenitor cell differentiation, immunofluorescence analyses were performed for a number of neural markers at different times post-differentiation (Figure 5F). Immediately after the proliferation phase and prior to differentiation, cells expressed the multipotential progenitor markers Sox 2 and Nestin, demonstrating lack of commitment to a more specified phenotype (Figure 5G). As expected, no expression of markers for mature neurons (NeuN, MAP2, TH) was detected at early time points. Nestin was highly expressed up to day 7 (Figure 5H), decreased at day 14 and was undetectable at later time points (not shown). Starting from day 14, mature neuronal markers were detected. NeuN expression was observed from day 14 to 21 of differentiation (Figure 5I) and data not shown. Similarly, MAP2 was detected from day 21 to 35 of differentiation (not shown). Finally, dopaminergic neuronal differentiation, as assessed by the expression of tyrosine hydroxylase $(\mathrm{TH})$ in MAP2+ cells, was detected in the same time window (Figure 5J and Figure 6A). Interestingly, confocal sectioning of PLL- and nECM-based cultures showed a marked difference in cell penetration of the substrate: while PLL-based cultures showed practically no depth in this analysis $(\mathrm{Z}=10 \mu \mathrm{m})$, nECM-based cultures presented neuronal cells deeply embedded within the substrate, as shown by a five fold increase in the $\mathrm{Z}$ axis length $(Z=50 \mu \mathrm{m}$; Figure $6 \mathrm{~B}-\mathrm{C}$ and Additional file 1 : Video S1 and Additional file 2: Video S2).

To quantify the differentiation of SVZ progenitors on both PLL- and nECM-based substrates, the numbers of cells positive for MAP2 and TH were counted. At early time points (day 10) the percentage of dopaminergic neurons was not significantly different $(\mathrm{p}>0.05)$ on both substrates $\left(54.2 \pm 10.3\right.$ vs $65.1 \pm 15.8 \% \mathrm{MAP}^{+} \mathrm{TH}^{+}$cells on PLL and nECM, respectively; Figure 6D-F). In contrast, a significant increase of dopaminergic neurons $(84.0 \pm 6.3 \%$ $\mathrm{MAP}^{+} \mathrm{TH}^{+}$neurons on $\mathrm{nECM}$ as compared to none on PLL) was found after 1 month in culture (Figure 6D-F).

In summary, the fact that SVZ progenitor cells maintained their multipotentiality for a week and thereafter differentiated towards dopaminergic neuron lineage for up to 35 days allowed us to temporarily map the expression of several proteins related to neuronal development, in what might be viewed as a relevant in vitro system for the assessment of unanswered questions related to neural development.

\section{Conclusions}

We have extended our previous observations on the ability of nECM to support in vitro neuronal differentiation, with the following achievements (i) we have recreated complex neuronal networks of embryonic rat hippocampal cells, and (ii) we achieved high levels of dopaminergic differentiation of SVZ progenitor cells. Furthermore, we showed proof-of-concept of the usefulness of this system to test the effect of added factors (as incorporated into the matrix) on neuronal behaviour. The biocompatible substrate enriched with nECM components represents a valid method to study neuronal development by using cells at different stages of commitment. Neural ECM-coated substrates increased culture maintenance window and neuronal differentiation efficiency as compared to cationic polymers such as PLL.

\section{Methods}

Animal care

All experiments were carried out in accordance with the guidelines established by the National Council on Animal Care and were approved by the local Animal Care Committee of the Universidad Autónoma of Madrid (UAM, Madrid, Spain) or the University of Basque Country (Spain) Animal Ethics committee, as relevant, following European Communities Council Directive of 22 September 2010 (2010/63/EU). Every possible effort was made to minimize animal suffering and the number of animals used.

\section{Isolation and culture of rat hippocampal cells}

Pregnant Sprague-Dawley rats (Charles River Laboratories International, Inc., Wilmington, USA) were sacrificed by $\mathrm{CO}_{2}$ inhalation and 18-day embryos (E18) were immediately removed by caesarean section. Hippocampi were dissected rapidly by using a Leica CLX 150× stereomicroscope (Leica Microsystems, Barcelona, Spain) under sterile conditions in cold $\left(4^{\circ} \mathrm{C}\right) \mathrm{PBS}$. The tissue was digested with $0.5 \mathrm{mg} / \mathrm{ml}$ papain (Sigma-Aldrich, Madrid, Spain) and $0.25 \mathrm{mg} / \mathrm{ml}$ DNAase (Sigma-Aldrich, Madrid, Spain). The enzymes were dissolved in a $\mathrm{Ca}^{2+}$ - and $\mathrm{Mg}^{2+}$-free PBS solution containing $1 \mathrm{mg} / \mathrm{ml}$ BSA (Sigma-Aldrich, Madrid, Spain) and $10 \mathrm{mM}$ glucose (Sigma-Aldrich, Madrid, Spain) at $37^{\circ} \mathrm{C}$ for $20 \mathrm{~min}$. The papain solution was replaced with $5 \mathrm{ml} \mathrm{Neurobasal}^{\mathrm{TM}}$ A Medium (Life Technologies Corporation, Paisley, UK) supplemented with 2\% B27 Supplement (Life Technologies Corporation, Paisley, UK), 1\% L-glutamine solution $200 \mathrm{mM}$ (Sigma-Aldrich, Madrid, Spain) and 1\% penicillin/streptomycin solution (Sigma-Aldrich, Madrid, Spain). The digested tissue was gently triturated by suction using a glass pipette flamed on the tip to avoid cellular damage. The cell suspension was centrifuged for $4 \mathrm{~min}$ at 1,200 rpm. The supernatant was removed and the cells resuspended in $5 \mathrm{ml}$ of medium 
and seeded on both PLL- and nECM-coated multiwell plates in the same maintenance medium at a density of 120,000 cells $/ \mathrm{ml}$. Cells were maintained in these conditions in a $5 \% \mathrm{CO} 2$ incubator at $37^{\circ} \mathrm{C}$.

\section{Isolation and differentiation of rat SVZ progenitor cells}

Neurosphere cultures were prepared from 4 to 7-day-old Sprague-Dawley rat pups (Charles River Laboratories International, Inc., Wilmington, USA). Subventricular zone (SVZ) tissue from 2-3 rat brains were isolated and minced with a McIllwain tissue chopper (H. Saur Laborbedarf,
Reutingen, Germany) and digested for $10 \mathrm{~min}$ at $37^{\circ} \mathrm{C}$ in $5 \mathrm{ml}$ of $0.25 \%$ trypsin/EDTA solution (Sigma-Aldrich, Madrid, Spain). Digestion was stopped by adding an equal volume of trypsin inhibitor (Sigma-Aldrich, Madrid, Spain) and $0.01 \%$ DNAse I for $5 \mathrm{~min}$ at room temperature. Cell suspension was centrifuged for $10 \mathrm{~min}$ at $600 \mathrm{~g}$ and the pellet was mechanically dissociated 25 times in NeuroCult medium (Stem Cell Inc., Grenoble, France) using a glass Pasteur pipette and 20 times using $1 \mathrm{ml}$ pipette tips. Nondissociated cells were decanted and the single cell suspension was counted using the Neubauer method. Cells were

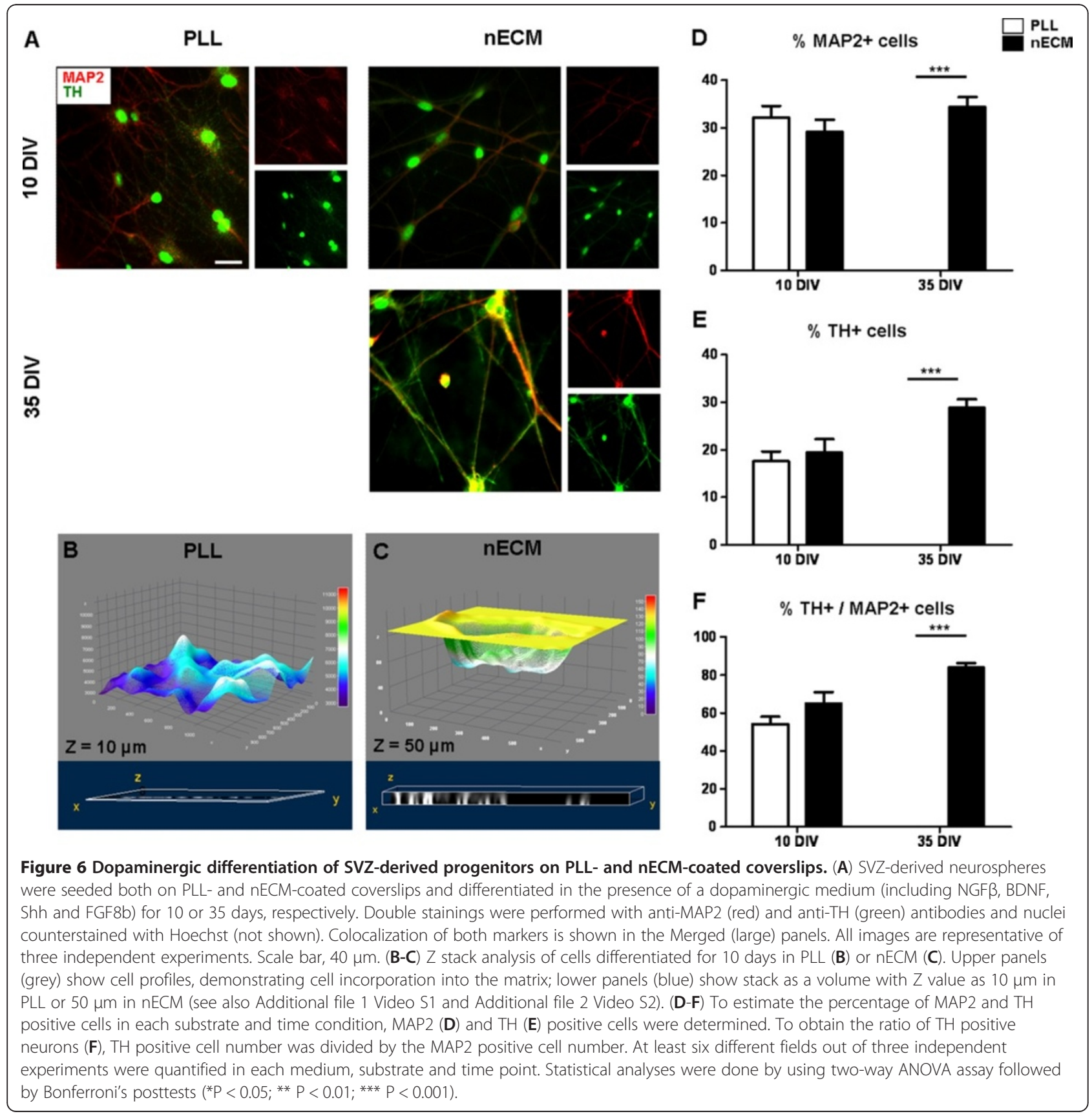


seeded in proliferation medium: NeuroCult with 10\% neural stem cell factors (both from Stem Cell Inc., Grenoble, France), 1\% L-glutamine solution $200 \mathrm{mM}$ (Sigma-Aldrich, Madrid, Spain), 1\% penicillin-streptomycin solution (Sigma-Aldrich, Madrid, Spain), 20 ng/ml EGF and $10 \mathrm{ng} / \mathrm{ml}$ FGF2 (both from Promega, Madrid, Spain), at a density of 10,000 cells $/ \mathrm{cm}^{2}$ and cultivated in suspension for 7 days at $37^{\circ} \mathrm{C}$ with $5 \% \mathrm{CO}_{2}$. EGF and FGF2 were added fresh every 2-3 days.

The differentiation of neurospheres on $12 \mathrm{~mm}$-diameter PLL- and nECM-coated coverslips (10 neurospheres/coverslip) was carried out in Neurobasal ${ }^{\mathrm{TM}}$ A Medium supplemented with 2\% B27 Supplement and 1\% N2 Supplement (all from Life Technologies Corporation, Paisley, UK), 10\% FBS (LGC Standards S.L.U., Barcelona, Spain), 1\% Lglutamine solution $200 \mathrm{mM}$ and $1 \%$ penicillin-streptomycin solution (both from Sigma-Aldrich, Madrid, Spain). Every two days, half of the medium was replaced and supplemented gradually and at different time periods up to 35 days with $50 \mathrm{ng} / \mathrm{ml}$ rat recombinant nerve growth factor $\beta$ (NGF $\beta$ ) (Sigma-Aldrich, Madrid, Spain), $50 \mathrm{ng} / \mathrm{ml}$ human recombinant brain derived neurotrophic factor (BDNF) (Sigma-Aldrich, Madrid, Spain), 200 ng/ml human recombinant Sonic hedgehog (Shh) (R\&D, Minneapolis, USA) and $200 \mathrm{ng} / \mathrm{ml}$ mouse recombinant fibroblastic growth factor $8 \mathrm{~b}$ (FGF8b) (R\&D, Minneapolis, USA).

\section{Development of neural extracellular matrix ( $\mathrm{nECM}$ )-coated subtrates}

Neural extracellular matrix (nECM)-coated substrates were developed as described [14]. Briefly, $12 \mathrm{~mm}$-diameter coverslips were incubated with a solution of Cultrex ${ }^{\circledR}$ basement membrane extract (BME) without phenol red $(8.32 \mathrm{mg} / \mathrm{ml}$; Trevigen, Gaithersburg, USA; it is a soluble form of basement membrane purified from EngelbrethHolm-Swarm tumor; the major components of this BME include laminin, collagen IV, entactin, and heparin sulfate proteoglycan), hyaluronan of low molecular weight (31 kDa, HLMW) (7.5 mg/ml; R\&D, Minneapolis, USA), Netrin-G1a and Netrin-4 (25 $\mathrm{mg} / \mathrm{ml}$; R\&D, Minneapolis, USA) in phosphate-buffered saline (PBS) (Life Technologies Corporation, Paisley, UK). For some experiments, chondroitin 4-sulfate glycosaminoglycan (Sigma-Aldrich, Madrid, Spain) was added to the mix together with hyaluronic acid. In order to polymerize and adsorb the matrix on the exposed glass surface they were kept for $24 \mathrm{~h}$ at $37^{\circ} \mathrm{C}$ in sterile conditions. Finally, excess PBS was eliminated and coverslips left to dry up for $1 \mathrm{~h}$ under laminar flow and UV light. As a control, PLL-coated coverslips were prepared by incubation of $12 \mathrm{~mm}$-diameter coverslips with a $0.01 \%$ solution of poly-L-lysine (Sigma-Aldrich, Madrid, Spain) in distilled water, followed by PBS washing and air drying under laminar flow for $1 \mathrm{~h}$.

\section{Immunofluorescence and confocal microscopy analyses}

Differentiating cells were washed with PBS and fixed in 4\% paraformaldehyde solution (Electron Microscopy Sciences, Hatfield, UK) for $20 \mathrm{~min}$ at room temperature. Cells were further washed with PBS and permeabilized for 1 hour in $0.3 \%$ Triton $^{\circledR}$ X-100 (Sigma-Aldrich, Madrid, Spain) in PBS (PBS-T) and 5\% normal donkey serum (Sigma-Aldrich, Madrid, Spain). After that, cells were incubated with the appropriate primary antibody diluted in PBS-T for $2 \mathrm{~h}$ at room temperature. Primary antibodies used were anti-Sox2 rabbit polyclonal (used at 1:1,000 dilution, Millipore \#AB5603, Billerica, USA), anti-nestin mouse monoclonal IgG1 (1:200, Millipore \# MAB353, Billerica, USA), anti-NeuN mouse monoclonal IgG1 (1:200, Millipore \#MAB377, Billerica, USA), antiGFAP mouse monoclonal IgG1 (1: 200; Dako, \#M0761, Denmark), anti-MAP2 mouse monoclonal IgG1 (1:200; Millipore \#MAB3418, Billerica, USA) and anti-tyrosine hydroxilase rabbit polyclonal (TH; 1:1,000; Millipore \# AB152, Billerica, USA) antibodies. After 3 washes (5 min each) fixed cells were incubated with the appropriate secondary antibody diluted in PBS-T for $1 \mathrm{~h}$ at room temperature. Secondary antibodies used were donkey antimouse Alexa Fluor ${ }^{\circledR} 488(1: 1,000)$ and donkey anti-rabbit Alexa Fluor ${ }^{\circledR} 546$ (1:1,000) (both from Life Technologies Corporation, Paisley, UK). Prior to embedding in Mowiol ${ }^{\circledR}$ mounting medium (Sigma-Aldrich, Madrid, Spain), cells were counterstained with $10 \mu \mathrm{g} / \mathrm{ml}$ Hoechst 33258 (Sigma-Aldrich, Madrid, Spain) for $5 \mathrm{~min}$ and washed with distilled water. Fluorescence images were obtained by using a Nikon Eclipse E600 FN microscope (objectives $10 \times$ and $20 \times$ ) coupled to Nikon Digital Sight and analysed with Nikon NIS-Elements. Confocal images were generated with a Zeiss LSM 510 microscope coupled to Zeiss Axion camera and analyzed with Zeiss ZEN image analysis software (2008; SP1.1; Carl Zeiss MicroImaging, S.L., Barcelona, Spain). Z stack was analyzed with the plug in $3 \mathrm{D}$ viewer of Image J software. In both cases, at least ten different fields out of three independent experiments $(n=3)$ were quantified.

\section{Quantification of cell viability with the MTT assay}

Cell viability was assessed by quantitative colorimetric assay with (3-(4,5-Dimethylthiazol-2-yl)-2,5-diphenyltetrazolium bromide (MTT), as previously described [44]. Briefly, a final concentration of $0.5 \mathrm{mg} / \mathrm{ml}$ MTT labelling reagent (SigmaAldrich, Madrid, Spain) in Neurobasal ${ }^{\mathrm{TM}}$ A Medium was added to each well containing embryonic hippocampal cells cultured for 8 days on control nECM- and chondroitin 4sulfate containing nECM-coated coverslips, and incubated for $2 \mathrm{~h}$. After that, colorimetric determination of MTT reduction was measured at $540 \mathrm{~nm}$ with a Kontron Instruments UVIKON 922 spectrophotometer. These experiments were repeated after treatment of embryonic 
hippocampal cells with several cytotoxic agents such as glutamate, oligomycin-rotenone $(\mathrm{O} / \mathrm{R})$ and amyloid beta 25:35 (A $\beta$ ) (all from Sigma-Aldrich, Madrid, Spain) for $24 \mathrm{~h}$. These experiments were performed with cells from day 7 to day 8 in culture. For statistical analyses, cells in each nECM-coated well in absence of toxic were taken as $100 \%$ of viability.

\section{Scanning electron microscopy analyses}

For Scanning Electron Microscopy (SEM) analyses, substrates with cells were fixed with Vitrosec ${ }^{\circledR} 70$ (Panreac Química S.A.U., Barcelona, Spain) for $20 \mathrm{~min}$ and stained with May-Grünwald's eosin methylene blue solution (Merck, Madrid, Spain). Samples were dried and mounted onto aluminium disks and coated with gold-argon. Imaging was performed on a JEOL JSM-5910-LV scanning electron microscope using a $20 \mathrm{kV}$ acceleration voltage. Samples were analyzed by an INCA-300 energy dispersed system (EDS) coupled to the microscope.

\section{Statistical analyses}

Data are expressed as the mean \pm SD of the number of independent experiments (n). Statistical significance of the results was assessed by using GraphPad Prism software (version 5.01 for Windows). Two-way analysis of variance with subsequent pairwise multiple comparison procedures (Bonferroni's posttests) was used to assess statistical significance between means. The statistical significance $(*)$ was established at $\mathrm{P}$-values $<0.05$ ( ${ }^{* * *} \mathrm{P}<0.01$; $\left.{ }^{* * * *} \mathrm{P}<0.001\right)$.

\section{Additional files}

Additional file 1: Video S1. Three-dimensional analysis of SVZ-derived progenitors differentiated on PLL-coated substrates for 10 days. A 3D projection of 40 consecutive confocal sections obtained from PLL-coated coverslips is shown. The depth of imaging was 14.6 microns with a thickness (interval) of 0.374 microns between sections. Video edition was done with ZEN 2008 and ImageJ software. Magnification: 480X.

Additional file 2: Video S2. Three-dimensional analysis of SVZ-derived progenitors differentiated on $n E C M$-coated substrates for 10 days. A 3D projection of 40 consecutive confocal sections obtained from nECM-coated coverslips is shown. The depth of imaging was 14.98 microns with a thickness (interval) of 0.384 microns between sections. Video edition was done with ZEN 2008 and ImageJ software. Magnification: 480X.

\section{Abbreviations}

nECM: Neural-like extracellular matrix; PLL: Poly-L-lysine; SVZ: Subventricular zone; Shh: Sonic hedgehog; PNNs: Perineural networks; NSCs: Neural stem cells; HLMW: Hyaluronan of low molecular weight; TH: Tyrosine hydroxilase.

\section{Competing interests}

The authors declare that they have no competing interests.

\section{Authors' contributions}

PGP and FC conceived the project, carried out the cellular studies, and analyzed all the experiments with contribution of its design from JIA and AGG. MM and NNG performed the pharmacological and immunomorphological studies under the supervision of $A G G$ and $P G P$, respectively. PGP, MM, AGG and FC drafted the manuscript while ALM and Al revised it critically for important intellectual content. FC, JAA, AGG, ALM and Al acquired funding necessary for the completion of the study. All authors read and approved the final manuscript.

\section{Acknowledgments}

This work was financed by grants from the Department of Industry and Commerce of the Basque Government (PC200829A-NEUROPATX, Spain) and Ministerio de Ciencia e Innovación (PI10/02871) from Spain. P.G.-P. was first supported by a fellowship from the "Iñaki Goenaga" Technology Centres Foundation (FCT-IG) (Technology Development Grants for Young Scientists, Spain) and then by a postdoctoral contract funded by Ministerio de Ciencia e Innovación (MICINN, Spain) [INNPACTO program (IPT-300000-2010-17). AGG and MM were supported by: (1) SAF 2010-21795, Ministerio de Economía y Competitividad (Spain); (2) RENEVAS-RETICS-RD06/0026, Instituto de Salud Carlos III (Spain); (3) CABICYC, UAM/Bioibérica (Spain). F.C. was supported by a project grant funded by Ministerio de Ciencia e Innovación (MICINN, Spain) (SAF2009-13463). A.I. was supported by the "Programa I3SNS" (CES09/015) from Instituto de Salud Carlos III and by Osakidetza-Servicio Vasco de Salud (Spain). We thank the continued support of Fundación Teófilo Hernando of Madrid (Spain).

\section{Author details}

${ }^{1}$ Tissue Engineering Laboratory, Department of Bioengineering, Instituto Biodonostia, Hospital Universitario Donostia, San Sebastian 20014, Spain. ${ }^{2}$ Neuroscience Area and CIBERNED, Instituto Biodonostia, Hospital Universitario Donostia, San Sebastian 20014, Spain. ${ }^{3}$ Instituto Teófilo Hernando de I + D del Medicamento. Departamento de Farmacología y Terapeútica and Servicio de Farmacología Clínica del IIS Hospital Universitario de La Princesa, Facultad de Medicina, Universidad Autónoma de Madrid (UAM), Madrid 28029, Spain. ${ }^{4}$ Department of Neuroscience and CIBERNED, University of Basque Country (UPV/EHU), Zamudio 48170, Spain.

${ }^{5}$ Basque Culinary Center R\&D, San Sebastian 20009, Spain.

Received: 8 January 2013 Accepted: 13 April 2013

Published: 18 April 2013

\section{References}

1. Corey JM, Feldman EL: Substrate patterning: an emerging technology for the study of neuronal behavior. Exp Neurol 2003, 184(Suppl 1):S89-S96.

2. Mina M, Kollar EJ, Bishop JA, Rohrbach DH: Interaction between the neural crest and extracellular matrix proteins in craniofacial skeletogenesis. Crit Rev Oral Biol Med 1990, 1(2):79-87.

3. Perris $R$, Perissinotto $D$ : Role of the extracellular matrix during neural crest cell migration. Mech Dev 2000, 95(1-2):3-21.

4. Celio MR, Spreafico R, De Biasi S, Vitellaro-Zuccarello L: Perineuronal nets: past and present. Trends Neurosci 1998, 21(12):510-515.

5. Giamanco KA, Morawski M, Matthews RT: Perineuronal net formation and structure in aggrecan knockout mice. Neuroscience 2010, 170(4):1314-1327.

6. Pizzorusso T, Medini P, Berardi N, Chierzi S, Fawcett JW, Maffei L: Reactivation of ocular dominance plasticity in the adult visual cortex. Science 2002, 298(5596):1248-1251.

7. Morawski M, Bruckner MK, Riederer P, Bruckner G, Arendt T: Perineuronal nets potentially protect against oxidative stress. Exp Neurol 2004, 188(2):309-315.

8. Galvin KA, Jones DG: Adult human neural stem cells for autologous cell replacement therapies for neurodegenerative disorders. NeuroRehabilitation 2006, 21(3):255-265.

9. Quinones-Hinojosa A, Chaichana K: The human subventricular zone: a source of new cells and a potential source of brain tumors. Exp Neurol 2007, 205(2):313-324.

10. Reynolds BA, Weiss S: Generation of neurons and astrocytes from isolated cells of the adult mammalian central nervous system. Science 1992, 255(5052):1707-1710.

11. Gage FH: Mammalian neural stem cells. Science 2000, 287(5457):1433-1438.

12. Palmer TD, Willhoite AR, Gage FH: Vascular niche for adult hippocampal neurogenesis. J Comp Neurol 2000, 425(4):479-494.

13. Temple S: The development of neural stem cells. Nature 2001 414(6859):112-117.

14. Garcia-Parra P, Cavaliere F, Maroto M, Bilbao L, Obieta I, Lopez de Munain A, Alava JI, Izeta A: Modeling neural differentiation on micropatterned 
substrates coated with neural matrix components. Front Cell Neurosci 2012, 6:10.

15. Galtrey CM, Fawcett JW: The role of chondroitin sulfate proteoglycans in regeneration and plasticity in the central nervous system. Brain Res Rev 2007, 54(1):1-18.

16. Zuo J, Neubauer D, Dyess K, Ferguson TA, Muir D: Degradation of chondroitin sulfate proteoglycan enhances the neurite-promoting potential of spinal cord tissue. Exp Neurol 1998, 154(2):654-662.

17. Kawashima H, Atarashi K, Hirose M, Hirose J, Yamada S, Sugahara K, Miyasaka M: Oversulfated chondroitin/dermatan sulfates containing GlcAbeta1/IdoAalpha1-3GalNAc(4,6-O-disulfate) interact with L- and P-selectin and chemokines. J Biol Chem 2002, 277(15):12921-12930.

18. Margolis RU, Margolis RK: Chondroitin sulfate proteoglycans as mediators of axon growth and pathfinding. Cell Tissue Res 1997, 290(2):343-348.

19. O'Donnell M, Chance RK, Bashaw GJ: Axon growth and guidance: receptor regulation and signal transduction. Annu Rev Neurosci 2009, 32:383-412.

20. Ravichandran R, Sundarrajan S, Venugopal JR, Mukherjee S, Ramakrishna S: Advances in Polymeric Systems for Tissue Engineering and Biomedical Applications. Macromol Biosci 2012, 12(3):286-311.

21. Torres-Costa V, Martinez-Munoz G, Sanchez-Vaquero V, Munoz-Noval A, Gonzalez-Mendez L, Punzon-Quijorna E, Gallach-Perez D, Manso-Silvan M, Climent-Font A, Garcia-Ruiz JP, et al: Engineering of silicon surfaces at the micro- and nanoscales for cell adhesion and migration control. Int $J$ Nanomedicine 2012, 7:623-630.

22. Discher $D E$, Janmey $P$, Wang $Y L$ : Tissue cells feel and respond to the stiffness of their substrate. Science 2005, 310(5751):1139-1143.

23. Martinez-Ramos C, Lainez S, Sancho F, Garcia Esparza MA, Planells-Cases R, Garcia Verdugo JM, Gomez Ribelles JL, Salmeron Sanchez M, Monleon Pradas M, Barcia JA, et al: Differentiation of postnatal neural stem cells into glia and functional neurons on laminin-coated polymeric substrates. Tissue Eng Part A 2008, 14(8):1365-1375.

24. Xiong Y, Zeng YS, Zeng CG, Du BL, He LM, Quan DP, Zhang W, Wang JM, Wu JL, Li Y, et al: Synaptic transmission of neural stem cells seeded in 3-dimensional PLGA scaffolds. Biomaterials 2009, 30(22):3711-3722.

25. Ma W, Tavakoli T, Derby E, Serebryakova Y, Rao MS, Mattson MP: Cell-extracellular matrix interactions regulate neural differentiation of human embryonic stem cells. BMC Dev Biol 2008, 8:90.

26. Tang $X$, Jang SW, Okada $M$, Chan CB, Feng $Y$, Liu $Y$, Luo SW, Hong $Y$, Rama $N$, Xiong WC, et al: Netrin-1 mediates neuronal survival through PIKE-L interaction with the dependence receptor UNC5B. Nat Cell Biol 2008, 10(6):698-706.

27. Rhodes KE, Fawcett JW: Chondroitin sulphate proteoglycans: preventing plasticity or protecting the CNS? J Anat 2004, 204(1):33-48.

28. Busch SA, Silver J: The role of extracellular matrix in CNS regeneration. Curr Opin Neurobiol 2007, 17(1):120-127.

29. Crespo-Santiago D: The extracellular matrix of the central nervous system: chondroitin sulphate type proteoglycans and neural repair. Rev Neurol 2004, 38(9):843-851.

30. Yamaguchi Y: Lecticans: organizers of the brain extracellular matrix. Cell Mol Life Sci 2000, 57(2):276-289.

31. Martin-de-Saavedra MD, del Barrio L, Canas N, Egea J, Lorrio S, Montell E, Verges J, Garcia AG, Lopez MG: Chondroitin sulfate reduces cell death of rat hippocampal slices subjected to oxygen and glucose deprivation by inhibiting p38, NFkappaB and iNOS. Neurochem Int 2011, 58(6):676-683.

32. Wang $H$, Katagiri $Y$, McCann TE, Unsworth E, Goldsmith P, Yu ZX, Tan F, Santiago L, Mills EM, Wang $Y$, et al: Chondroitin-4-sulfation negatively regulates axonal guidance and growth. J Cell Sci 2008, 121(Pt 18):3083-3091.

33. Canas N, Valero T, Villarroya M, Montell E, Verges J, Garcia AG, Lopez MG: Chondroitin sulfate protects SH-SY5Y cells from oxidative stress by inducing heme oxygenase-1 via phosphatidylinositol 3-kinase/Akt. J Pharmacol Exp Ther 2007, 323(3):946-953.

34. McKeon RJ, Jurynec MJ, Buck CR: The chondroitin sulfate proteoglycans neurocan and phosphacan are expressed by reactive astrocytes in the chronic CNS glial scar. J Neurosci 1999, 19(24):10778-10788.

35. Bradbury EJ, Carter LM: Manipulating the glial scar: chondroitinase $A B C$ as a therapy for spinal cord injury. Brain Res Bull 2011, 84(4-5):306-316.

36. Bunge MB: Novel combination strategies to repair the injured mammalian spinal cord. J Spinal Cord Med 2008, 31(3):262-269.

37. Carter LM, Starkey ML, Akrimi SF, Davies M, McMahon SB, Bradbury EJ: The yellow fluorescent protein (YFP-H) mouse reveals neuroprotection as a novel mechanism underlying chondroitinase $A B C$-mediated repair after spinal cord injury. J Neurosci 2008, 28(52):14107-14120.

38. Cavaliere F, Urra O, Alberdi E, Matute C: Oligodendrocyte differentiation from adult multipotent stem cells is modulated by glutamate. Cell Death Dis 2012, 3:e268.

39. Fuccillo $M$, Joyner $A L$, Fishell $G$ : Morphogen to mitogen: the multiple roles of hedgehog signalling in vertebrate neural development. Nat Rev Neurosci 2006, 7(10):772-783.

40. Machold R, Hayashi S, Rutlin M, Muzumdar MD, Nery S, Corbin JG, Gritli-Linde A, Dellovade T, Porter JA, Rubin LL, et al: Sonic hedgehog is required for progenitor cell maintenance in telencephalic stem cell niches. Neuron 2003, 39(6):937-950.

41. Ruiz i Altaba A, Palma V, Dahmane N: Hedgehog-Gli signalling and the growth of the brain. Nat Rev Neurosci 2002, 3(1):24-33.

42. Vitalis T, Cases O, Parnavelas JG: Development of the dopaminergic neurons in the rodent brainstem. Exp Neurol 2005, 191(Suppl 1):S104-S112.

43. Ye W, Shimamura K, Rubenstein JL, Hynes MA, Rosenthal A: FGF and Shh signals control dopaminergic and serotonergic cell fate in the anterior neural plate. Cell 1998, 93(5):755-766

44. Denizot F, Lang R: Rapid colorimetric assay for cell growth and survival. Modifications to the tetrazolium dye procedure giving improved sensitivity and reliability. J Immunol Methods 1986, 89(2):271-277.

doi:10.1186/1471-2202-14-48

Cite this article as: García-Parra et al:: A neural extracellular matrix-based method for in vitro hippocampal neuron culture and dopaminergic differentiation of neural stem cells. BMC Neuroscience 2013 14:48.

\section{Submit your next manuscript to BioMed Central and take full advantage of:}

- Convenient online submission

- Thorough peer review

- No space constraints or color figure charges

- Immediate publication on acceptance

- Inclusion in PubMed, CAS, Scopus and Google Scholar

- Research which is freely available for redistribution 